\title{
Ribosomal Genes Activity in Aged Down Syndrome Subjects
}

\author{
Alaíde Gonçalves, Yara Regina Bianchini Ávalos, Elizabeth Suchi Chen, Bianca Borsatto-Galera, \\ Roger William De Lábio, Spencer Luiz Marques Payão and Marília de Arruda Cardoso Smith*
}

\author{
Disciplina de Genética - Departamento de Morfologia e Genética, UNIFESP/EPM, Rua Botucatu, 740 - Vila \\ Clementino, CEP: 04023-900, São Paulo, SP, Brasil
}

\begin{abstract}
Objective: We aimed to investigate whether rRNA 28S/18S levels decrease with aging in Down Syndrome (DS) individuals and whether these decreased levels are tissue-specific.

Methods: We investigated mature rRNA 28S/18S levels by Northern Blotting in blood cells from 21 younger and 21 older DS individuals in comparison to 42 age-sex-matched controls. We also investigated these levels in oral mucosa and in blood cells from the same DS individuals.

Results: All DS subjects showed no clinical signs of dementia at the time of the study. We did not detect differences in rRNA 28S/18S levels among DS and control groups concerning either aging process or cell types.

Conclusions: Aging process in DS individuals was not characterized by reduced rDNA transcriptional activity and did not indicate a preclinical marker of AD in older DS subjects.
\end{abstract}

Keywords: Down`s syndrome, Trisomy 21, Ageing, Ribosomal Genes Expression, rRNA.

\section{INTRODUCTION}

Loss of ribosomal genes has been observed in the aging process of many cell types, such as nervous tissue, cardiac and skeletal striated muscles as well as inhuman adipocytes. Alterations in rRNA biogenesis have also been associated with many diseases $[1,2]$. A reduced ribosomal genes transcriptional activity and a preferential degradation of the major $28 \mathrm{~S}$ subunit in relation to $18 \mathrm{~S}$ have been verified in leukocytes from patients with Alzheimer disease (AD) [3-5].

Most of the clinical signs associated with normal aging occur prematurely in adult individuals with Down syndrome (DS) who also show early cognitive decline and generally develop neuropathological signs of AD [6].

A previous study conducted by our laboratory confirmed the progressive loss of chromosome 21 with age, in 2-4\% of cells, in DS individuals, originally reported by Percy et al. [7], who called it an "occult mosaicism". Therefore, older DS should be considered individuals with low levels of cellular mosaicism which could contribute to the phenotypic variance and to $\mathrm{AD}$.

We previously reported a significant decrease of satellite association and AgNOR staining frequencies in lymphocyte chromosomes carrying Nucleolar Organizer Regions (NOR) from older DS in relation to younger DS [8]. Literature shows controversial evidence regarding AgNOR staining frequencies in chromosomes from older DS individuals.

\footnotetext{
*Address correspondence to this author at the Disciplina de Genética Departamento de Morfologia e Genética, UNIFESP/EPM, Rua Botucatu, 740 - Vila Clementino, CEP: 04023-900, São Paulo, SP, Brasil; Tel: 55-11-5576 4260; Fax: 55-11-5576 4260;

E-mail: macsmith.morf@epm.br
}

Increase in the rDNA expression has been detected in lactents and infants with DS using this technique and Dermitas [9] proposed that this increase in ribosome biogenesis leading to disturbed protein synthesis may contribute to DS phenotype [9-13].

Reduction in the ability or protein synthesis, quantity of 5.8S and 5S rRNA, tRNA and an increase in the oxidation of RNAs were detected in the cerebral cortex of post-mortem patients exhibiting mild cognitive impairment and AD [14, 15]. The authors proposed that ribosome function alterations may be an important marker in AD pathogenesis. Addicionally, Honda et al. [16] suggested that rRNA acts as a redox center within the neuronal cells probably associated with reduction of protein synthesis.

The aim of our study was to investigate rDNA transcriptional activity through mature rRNA 28S/18S levels in younger and older DS subjects in two distinct tissues showing different embryonic origins and cell types and in agesex-matched-controls. Thus, we selected blood cells, mesoderm-derived cells and oral mucosa cells, neuroectodermderived cells which share the same embryonic origin as neural cells. This is the first report comparing ribosomal transcriptional function in two different tissues from younger and older DS individuals.

\section{METHODS}

\section{Procedure}

Patients were recruited at the Center of Dental Treatment for Mentally Disabled (CAOE). 42 DS individuals and 42 controls were separated into 4 groups: younger DS patients (YD); elder DS patients (ED); younger control subjects 
(YC); elder control subjects (EC). YD group ranged 6-21 years old and OD presented 35-54 years old. This cut-off was based on literature researches that verified premature aging in DS at 30 years old [17]. Table 1 summarizes sample's characteristics.

Five millilitres of peripheral blood as well as biopsy samples from the healthy maxillary gingival tissue were collected from each patient. This study was approved by the National Health Research Ethics Committee, Ministério da Saúde, Brazil. Patients and their caregivers gave us an informed consent according to the Declaration of Helsinki.

DS diagnosis was obtained by clinical and cytogenetic exams. We have only included patients with three distinct copies of chromosome 21 in all analyzed metaphases. At the time examination, none of the patients presented any clinical signs or symptoms of dementia.

Total RNA was extracted from blood and gingival biopsy samples using QIAamp RNA Blood Mini Kit ${ }^{\circledR}$ (QIAGEN), following the manufacturer's instructions. rDNA regions were amplified by polymerase chain reaction (PCR), and $\beta$ actin gene $(A C T B)$ was used as an internal control. Primers used in the reaction were: $18 \mathrm{~S}$ sense 5'-ATGGTAGTCGCCGTGCCTACCAT; 18S antisense 5'-CCCGTGTTGAGTCAAATTAAGCCGCAG; 28S sense 5'-CAGCAGCACTCGCCGAATCCC; 28S antisense 5'- GCGCCCTGCCCTTCACAAAGA; ACTB sense 5'-ATGTACGTTGCTATCCAGGC; ACTB antisense 5'-CCTTAATGTCACGCACGATTT.

Ten micrograms of extracted RNA were separated by denaturing agarose gel electrophoresis containing $1 \%$ formaldehyde and then, transferred to Hybond-N+ nylon membrane (GE). Gene Image kit and CDP Star Detection Module kit (GE, USA) were used to label and detect the probes according to the manufacturer's protocol. Hybridization signals of each probe were quantified by Alpha Imager 2000 (Alpha Innotech Corporation $^{\mathrm{TM}}$ ).

To verify the effect of aging process on rDNA activity, we measured rRNA ratio levels and compared the results of younger and elder groups using ANOVA. Moreover, we also

Table 1. Characterization of the sample. $\mathrm{F}=$ female; $\mathrm{M}=$ male; $\mathrm{YD}=$ young $\mathrm{DS} ; \mathrm{ED}=\mathrm{Elder} \mathrm{DS}$; YC = young control; $\mathrm{EC}=\mathrm{Elder}$ control. SD=Standard Deviation

\begin{tabular}{|c|c|c|c|c|c|}
\hline Subject & Tissue & \multicolumn{4}{|c|}{$\operatorname{Age}($ Years)/Sex } \\
\hline 2 & Oral mucosa/ blood & $14 / \mathrm{F}$ & $43 / \mathrm{F}$ & $14 / \mathrm{M}$ & $67 / M$ \\
\hline 3 & Oral mucosa/ blood & $20 / \mathrm{F}$ & $51 / \mathrm{M}$ & $18 / \mathrm{F}$ & $70 / \mathrm{M}$ \\
\hline 5 & Oral mucosa/ blood & $11 / \mathrm{M}$ & $38 / \mathrm{M}$ & $14 / \mathrm{M}$ & 73/M \\
\hline 6 & Oral mucosa/ blood & $14 / \mathrm{F}$ & $44 / F$ & $17 / \mathrm{M}$ & 78/M \\
\hline 7 & Oral mucosa/ blood & $11 / \mathrm{F}$ & $41 / \mathrm{F}$ & $19 / \mathrm{M}$ & $68 / \mathrm{F}$ \\
\hline 8 & Oral mucosa/ blood & $17 / \mathrm{F}$ & $44 / \mathrm{F}$ & $22 / \mathrm{F}$ & $70 / \mathrm{F}$ \\
\hline 11 & Oral mucosa/ blood & $21 / \mathrm{M}$ & $50 / \mathrm{M}$ & 20/M & $72 / \mathrm{F}$ \\
\hline 12 & Blood & $16 / \mathrm{M}$ & $35 / \mathrm{F}$ & $19 / \mathrm{F}$ & $61 / M$ \\
\hline 13 & Blood & $12 / \mathrm{F}$ & $35 / \mathrm{M}$ & $19 / \mathrm{F}$ & $71 / \mathrm{F}$ \\
\hline 14 & Blood & $9 / \mathrm{F}$ & $47 / \mathrm{F}$ & $19 / \mathrm{F}$ & $70 / \mathrm{F}$ \\
\hline 15 & Blood & $17 / M$ & $43 / F$ & $18 / \mathrm{F}$ & $62 / \mathrm{M}$ \\
\hline 16 & Blood & $12 / \mathrm{M}$ & $46 / \mathrm{M}$ & $18 / \mathrm{F}$ & $72 / \mathrm{F}$ \\
\hline 17 & Blood & $9 / \mathrm{M}$ & $38 / \mathrm{M}$ & 20/M & $70 / \mathrm{M}$ \\
\hline
\end{tabular}


compared intraindividual measurements to evaluate the effect of each tissue on rDNA activity by paired-samples t-test. For this proposal, a subsample of 10 individuals composed each group. p-value lower than 0.05 was considered significant.

\section{RESULTS}

Whereas our paired-samples t-test results showed no significant differences between blood and gingival samples within each group (YD: $\mathrm{p}=0.229$; ED: $\mathrm{p}=0.089$; YC: $\mathrm{p}=0.085$; $\mathrm{EC}: \mathrm{p}=0.34)$, ED patients presented higher level of rRNA $28 \mathrm{~S} / 18 \mathrm{~S}$ in gingival than in blood cells $(\mathrm{p}=0.089)$, although the statistical significance was not reached. In contrast, gingival cells from YC showed lower 28S/18S rRNA ratio levels than blood cells $(\mathrm{p}=0.085)$. These controversial findings might be explained by the association of elevated level of cell repair with increased protein synthesis related to periodontal diseases, long-lasting healing process and inflammatory responses in gingival cells from elder DS [1821].

Our ANOVA results showed no difference of 28S/18S rRNA ratios among groups $(\mathrm{F}=0.283, \mathrm{p}=0.959)$, even when blood and gingival samples were analyzed separately $(\mathrm{F}=0.056, \mathrm{p}=0.982 ; \mathrm{F}=0.389, \mathrm{p}=0.772$, respectively $)$. Using a smaller sample and a different technique, we have previously reported no significant differences in $28 \mathrm{~S}: 18 \mathrm{~S}$ rRNA ratios in blood cells from younger and older DS [22]. These findings confirmed another study in lymphocytes and skin fibroblasts from DS adult individuals and controls by dot blot [23].

Our results concerning mature rRNA $28 \mathrm{~S} / 18 \mathrm{~S}$ levels in blood and in oral mucosa cells from the same DS and control individuals did not differ between these tissues (Table 2).
The comparison of rRNA levels among all groups including both tissues also failed to reveal significant differences (Table 2). Moreover, rRNA levels in blood cells from 42 DS and 42 age-sex-matched controls did not differ significantly (data not shown).

\section{DISCUSSION}

Our results confirm those of McQuillan \& Choo [23] who observed no significant differences in rRNA levels in lymphocyte and skin fibroblast cells from eight DS adults and controls using slot dot procedure. Our findings also confirm those from Borsatto-Galera [22] in our laboratory, who verified no significant differences in mature rRNA levels in blood cells from eight young and eight older DS individuals in comparison with age-sex-matched controls using the same technique.

The rRNA biogenesis is a complex and multi step process beginning in NOR chromosome regions and nucleoli where pre-rRNA is modified by almost 80 small nucleolar RNPs (snoRNPs), by other 150 non-ribosomal proteins and by many non-coding small RNAs. An efficient transcription of rDNA by Pol 1 needs the formation of a preinitiation complex (PIC) which includes Upstream Binding Factor (UBF) and Selectivity Factor 1 (SF1) on the promoter region. UBF mediates recruitment of Pol I by its interaction with this enzyme as well as with many other factors. A subset of small subunit ribosomal proteins (snoRNPs) and nonribosomal factors assemble co-transcriptionally with the preRNA to form a terminal knob, the first pre-ribosomal particle on the path to the small ribosomal subunit.

Synthesis of rRNA is also influenced by some genes related to cell cycle, cell proliferation and cell differentiation,

Table 2. rRNA 28S/18S from gingival (G) and blood (B) tissues from each individual: younger Down syndrome (YDB and YDG), older Down syndrome (ODB and ODG), Younger controls (YCB and YCG) and elderly controls (OCB and OCG). SD= standard deviation; $p=p$ value

\begin{tabular}{|c|c|c|c|c|c|c|c|c|}
\hline \multirow{2}{*}{ Subject } & \multicolumn{2}{|c|}{ YD } & \multicolumn{2}{|c|}{ OD } & \multicolumn{2}{|c|}{ YC } & \multicolumn{2}{|c|}{ OC } \\
\hline & B & $\mathbf{O M}$ & B & OM & B & $\mathbf{O M}$ & B & OM \\
\hline 1 & 0.90 & 0.86 & 0.93 & 0.91 & 1.03 & 1.04 & 0.92 & 1.10 \\
\hline 2 & 0.68 & 0.72 & 0.61 & 0.66 & 0.72 & 0.63 & 0.61 & 0.62 \\
\hline 3 & 0.92 & 0.77 & 0.83 & 0.9 & 0.91 & 0.57 & 0.81 & 0.89 \\
\hline 4 & 1.12 & 0.97 & 1.22 & 1.24 & 1.26 & 1.06 & 1.46 & 1.32 \\
\hline 5 & 1.24 & 1.19 & 1.16 & 1.11 & 1.23 & 1.23 & 1.04 & 1.17 \\
\hline 6 & 0.86 & 0.86 & 0.92 & 0.97 & 0.72 & 0.77 & 0.9 & 0.80 \\
\hline 7 & 1.05 & 1.14 & 0.95 & 1.00 & 0.97 & 0.97 & 0.89 & 0.91 \\
\hline 8 & 0.94 & 1.00 & 0.98 & 0.95 & 1.00 & 1.02 & 1.06 & 0.96 \\
\hline 9 & 1.07 & 0.8 & 1.18 & 1.23 & 1.21 & 1.19 & 1.21 & 0.74 \\
\hline 10 & 1.12 & 1.13 & 1.12 & 1.21 & 1.16 & 0.90 & 1.15 & 0.94 \\
\hline Mean & 0.99 & 0.94 & 0.99 & 1.02 & 1.02 & 0.94 & 1.01 & 0.95 \\
\hline$\pm \mathrm{SD}$ & \pm 0.16 & \pm 0.17 & \pm 0.19 & \pm 0.18 & \pm 0.20 & \pm 0.12 & \pm 0.24 & \pm 0.28 \\
\hline Paired $\mathrm{t}-$ Test $\mathrm{p}=$ & \multicolumn{2}{|c|}{0.229} & \multicolumn{2}{|c|}{0.089} & \multicolumn{2}{|c|}{0.085} & \multicolumn{2}{|c|}{0.34} \\
\hline
\end{tabular}


such as $T P 53, R B$ and $M Y C$, whose importance in this process is becoming more and more evident. Furthermore, ribosomal RNA synthesis by Pol I is crucially dependent upon nutrient availability and drives ribosome biogenesis, a process close linked to cell growth and proliferation [24-27].

Recent experiments have shown that rRNA gene expression is regulated by chromatin remodeling factors, small non-coding RNAs and epigenetic events, including histone acetylation and methylation and DNA methylation in many organisms. These epigenetic regulation mechanisms also involve a reallocation of the majority of rDNA from perinucleolar heterochromatin into the nucleolus [25, 28].

The regulatory role of the new non-coding rRNA transcripts that correspond to poliadenylated RNAs containing portions of $18 \mathrm{~S}$ and $28 \mathrm{~S}$ rRNA genes is still being elucidated [29]. It is well known that AgNOR staining counts detect proteins complexed with pre-rRNA in the beginning of rRNA biogenesis which occur in NOR regions and nucleoli and are substract for staining reaction. On the other hand the analysis using Northern blotting technique detects the presence of mature rRNA levels subunits after pre-RNA processing and exportation to the cytoplasm compartment [25].

The discrepancy between our present findings related to mature rRNA levels and our previously results, analyzing rDNA transcriptional state through AgNOR staining technique, was probably due to the different experimental strategies and approaches to evaluate rRNA biogenesis, detecting different molecular elements, cell cycle phases, cell proliferation and differentiation conditions as well as the responses to environmental modifications.

The dynamic nature of nucleoli has been progressively clarified, including the nucleolar composition changing in response to external stimuli. Epigenetic regulation establishes an interface between environmental responses and gene determination.

Although there are few reports comparing AgNOR staining counts in human chromosomes with slot dot techniques they show a good agreement between the cytological approach and the molecular investigation [3-5].

Previous works conducted by our laboratory have confirmed an age-related loss of chromosome 21 in $2-4 \%$ of cells from DS, classified as "occult mosaicism" [7, 8]. Moreover, FISH interphase technique revealed that lymphocyte cells were more prone to lose $21 \mathrm{q}$ telomere regions than oral mucosa cells obtained from the same 11 DS individuals, aged from 5-54 years old. The authors proposed that cell repair was more efficient in oral mucosa cells mainly due to the higher proliferation rate of this tissue than to a germ layer origin $[8,30]$.

Transcriptional profile in blood cells of DS and AD using different methodologies, such as SAGE libraries and distinct microarray platforms revealed, as expected, common and distinct expression of some families of genes in both diseases.

Fehlbaum-Beurdeley et al. [31] verified 133 genes in blood cells whose expression pattern may distinguish AD patients from controls. These genes were involved in five major pathways occurring in macrophages and lymphocytes, such as to the transforming growth factor-beta signaling, oxidative stress, cytoskeletal organization, inflammatory and immune responses, lipid-raft, cholesterol homeostasis and the ubiquitin proteasome system. These findings confirmed previous results obtained in the same cells by Maes et al. [32], who also verified differential expression of genes involved in DNA repair and in novel pathways of betaamyloid deposition.

Transcriptional analysis in blood cells and in lymphoblastoid cells of Down's syndrome subjects revealed that most of the chromosome 21 transcripts are compensated for the gene-dosage effect and some were highly expressed [33, 34]. These highly expressed genes were related to some major functions, such as cytosolic ribosome, protein biosynthesis, immune response, regulation of protein metabolism, RNA processing, oxidative phosphorylation and cell cycle among others [33].

A briefly comparison between DS and AD transcriptional profiles reveal some distinct as well some common genes expressed in both disorders. A further critical and methodological accurate comparison of profiles of DS and AD may provide distinct transcriptome related to each disease.

These distinct transcriptome profiles may also be responsible for the discrepancy between our AgNOR and rRNA 28S/18S findings in DS and AD subjects. With certainty these studies still requires replication of data under many aspects. Furthermore, recent advances associated with rRNA biogenesis, gene expression and proteomics are progressively clarifying many aspects of these complex and dynamic processes.

\section{CONCLUSION}

Therefore, the aging process in DS individuals was not characterized by reduced rDNA transcriptional activity and did not indicate a preclinical marker of AD in older DS subjects.

\section{ACKNOWLEDGEMENTS}

This study was supported by FAPESP (Fundação de Amparo à Pesquisa do Estado de São Paulo, Brazil), CNPq (Conselho Nacional de Desenvolvimento Cientifico e Tecnológico, Brasil) and a fellowship grant from PROINTER/PROPe (Pró-reitoria de pesquisa/Fundo de Internacionalização da pesquisa da UNESP, Brazil). The authors are grateful to all the participants with DS and their caregivers, supervisor and nurses of the Center for Dental Treatment for the Mentally Disabled (CAOE) of Araçatuba School of Dentistry State University of São Paulo (UNESP), for their collaboration and dedication to this research project. We would like to thank Karina Vieira Casatti for reviewing the manuscript. The authors declare no conflict of interest.

\section{REFERENCES}

[1] Strehler BL, Chang MP, Johnson LK. Loss of hybridizable ribosomal DNA from human post-mitotic tissues during aging: I. Agedependent loss in human myocardium. Mech Ageing Dev 1979; 11(5-6): 371-8

[2] Zafiropoulos A, Tsentelierou E, Linardakis M, Kafatos A, Spandidos DA. Preferential loss of 5S and 28S rDNA genes in human adipose tissue during ageing. Int J Biochem Cell Biol 2005; 37(2): 409-15. 
[3] da Silva AM, Payao SL, Borsatto B, Bertolucci PH, Smith MA. Quantitative evaluation of the rRNA in Alzheimer's disease. Mech Ageing Dev 2000; 120(1-3): 57-64.

[4] Payao SL, Smith M, Kormann-Bortolotto MH, Toniolo J. Investigation of the nucleolar organizer regions in Alzheimer's disease. Gerontology 1994; 40(1): 13-7.

[5] Payao SL, Smith MA, Winter LM, Bertolucci PH. Ribosomal RNA in Alzheimer's disease and aging. Mech Ageing Dev 1998; 105(3): 265-72.

[6] Nistor M, Don M, Parekh M, et al. Alpha- and beta-secretase activity as a function of age and beta-amyloid in Down syndrome and normal brain. Neurobiol Aging 2007; 28(10): 1493-506.

[7] Percy ME, Markovic VD, Dalton AJ, et al. Age-associated chromosome 21 loss in Down syndrome: possible relevance to mosaicism and Alzheimer disease. Am J Med Genet 1993; 45(5): 584-8.

[8] Borsatto B, Smith M. Reduction of the activity of ribosomal genes with age in Down's syndrome. Gerontology 1996; 42(3): 147-54.

[9] Demirtas H. AgNOR status in Down's syndrome infants and a plausible phenotype formation hypothesis. Micron 2009; 40(5-6): 511-8.

[10] Demirtas H, Imamoglu N, Donmez H, Cucer N, Yilmaz A, Candemir Z. Condensed chromatin surface and NORs surface enhancement in mitogen-stimulated lymphocytes of Down syndrome patients. Ann Genet 2001; 44(2): 77-82.

[11] Hamurcu Z, Demirtas H, Patiroglu T, Kumandas S. Nuclear protein contents in peripheral blood mononuclear cells of trisomy 21 infants. Cytometry B Clin Cytom 2008; 74(2): 128-32.

[12] Imamoglu N, Demirtas H, Donmez-Altuntas H, Hamurcu Z, Ilten A. NOR expression increases on metaphase chromosomes of Down syndrome lymphocytes in concordance with mitogen concentration in culture medium. Cytometry B Clin Cytom 2005; 66(1): 36-9.

[13] Yilmaz SI, Demirtas H. AgNOR increase in buccal epithelial cells of trisomy 21 infants. Micron 2008; 39(8): 1262-5.

[14] Ding Q, Markesbery WR, Chen Q, Li F, Keller JN. Ribosome dysfunction is an early event in Alzheimer's disease. J Neurosci 2005; 25(40): 9171-5.

[15] Sanij E, Hannan RD. The role of UBF in regulating the structure and dynamics of transcriptionally active rDNA chromatin. Epigenetics 2009; 4(6): 374-82.

[16] Honda K, Smith MA, Zhu X, et al. Ribosomal RNA in Alzheimer disease is oxidized by bound redox-active iron. J Biol Chem 2005; 280(22): 20978-86.

[17] Ferreira FL, Pra D, Martino-Roth MG, Garcias GL. Buccal micronucleus frequency is associated with age in Down syndrome. Genet Mol Res 2009; 8(4): 1231-7.

[18] Bagic I, Verzak Z, Cukovic-Cavka S, Brkic H, Susic M. Periodontal conditions in individuals with Down's syndrome. Coll Antropol 2003; 27 Suppl 2: 75-82.

[19] Chaushu S, Becker A, Chaushu G, Shapira J. Stimulated parotid salivary flow rate in patients with Down syndrome. Spec Care Dentist 2002; 22(1): 41-4.
[20] Chaushu S, Chaushu G, Zigmond M, et al. Age-dependent deficiency in saliva and salivary antibodies secretion in Down's syndrome. Arch Oral Biol 2007; 52(11): 1088-96.

[21] Reuland-Bosma W, Liem RS, Jansen HW, van Dijk LJ, van der Weele LT. Morphological aspects of the gingiva in children with Down's syndrome during experimental gingivitis. J Clin Periodontol 1988; 15(5): 293-302.

[22] Borsatto-Galera B. Telômeros e genes ribossômicos no envelhecimento de indivíduos com síndrome de Down. São Paulo: Universidade Federal de São Paulo; 2000.

[23] McQuillan CI, Choo KH. Comparison of total cellular DNA, mRNA, and rRNA levels between normals and Down syndrome patients. J Inherit Metab Dis 1992; 15(1): 112-20.

[24] Kressler D, Hurt E, Bassler J. Driving ribosome assembly. Biochimi Biophys Acta 2010; 1803(6): 673-83.

[25] Bartova E, Horakova AH, Uhlirova R, et al. Structure and epigenetics of nucleoli in comparison with non-nucleolar compartments. J Histochem Cytochem 2010; 58(5): 391-403.

[26] Birch JL, Zomerdijk JC. Structure and function of ribosomal RNA gene chromatin. Biochem Soc Transact 2008; 36(Pt 4): 619-24.

[27] Fumagalli S, Di Cara A, Neb-Gulati A, et al. Absence of nucleolar disruption after impairment of $40 \mathrm{~S}$ ribosome biogenesis reveals an rpL11-translation-dependent mechanism of p53 induction. Nat Cell Biol 2009; 11(4): 501-8.

[28] Caperta AD, Neves N, Viegas W, Pikaard CS, Preuss S. Relationships between transcription, silver staining, and chromatin organization of nucleolar organizers in Secale cereale. Protoplasma 2007; 232(1-2): 55-9.

[29] Merl J, Jakob S, Ridinger K, et al. Analysis of ribosome biogenesis factor-modules in yeast cells depleted from pre-ribosomes. Nucleic Acids Res 2010; 38(9): 3068-80.

[30] de Arruda Cardoso Smith M, Borsatto-Galera B, Feller RI, et al. Telomeres on chromosome 21 and aging in lymphocytes and gingival fibroblasts from individuals with Down syndrome. J Oral Sci 2004; 46(3): 171-7.

[31] Fehlbaum-Beurdeley P, Jarrige-Le Prado AC, Pallares D, et al. Toward an Alzheimer's disease diagnosis via high-resolution blood gene expression. Alzheimers Dement 2010; 6(1): 25-38.

[32] Maes OC, Xu S, Yu B, Chertkow HM, Wang E, Schipper HM. Transcriptional profiling of Alzheimer blood mononuclear cells by microarray. Neurobiol Aging 2007 ; 28(12): 1795-809.

[33] Sommer CA, Pavarino-Bertelli EC, Goloni-Bertollo EM, HenriqueSilva F. Identification of dysregulated genes in lymphocytes from children with Down syndrome. Genome 2008; 51(1): 19-29.

[34] Ait Yahya-Graison E, Aubert J, Dauphinot L, et al. Classification of human chromosome 21 gene-expression variations in Down syndrome: impact on disease phenotypes. Am J Hum Genet 2007; 81(3): 475-91. 